\title{
Tütün Tohumuna Uygulanan Bazı İyileștirici Ön Uygulamaların Çimlenme ve Fide Çıkış Performansına Etkisi
}

\author{
Sıdıka Ekren ${ }^{1 *}$, Merter Güngör ${ }^{1}$ \\ ${ }^{1}$ Ege Üniversitesi Ziraat Fakültesi Tarla Bitkileri Bölümü Bornova/İzmir (ORCID: 0000-0002-6812-9586)
}

(İlk Geliş Tarihi 19 Şubat 2020 ve Kabul Tarihi 17 Mart 2020)

(DOI: 10.31590/ejosat. 691139)

ATIF/REFERENCE: Ekren, S. \& Güngör, M. (2020). Tütün Tohumuna Uygulanan Bazı İyileştirici Ön Uygulamaların Çimlenme ve Fide Çıkış Performansına Etkisi. Avrupa Bilim ve Teknoloji Dergisi, (18), 591-598.

$\ddot{O} \mathbf{z}$

Bu çalışma tütün tohumuna uygulanan bazı iyileştirici ön uygulamaların fide kalitesine etkilerini belirlemek amacıyla yürütülmüsştür. İzmir-Özbaş tütün çeşidinin kullanıldığı araştırma Tesadüf Parselleri Deneme Deseni’ne göre üç tekerrürlü olarak kurulmuştur. Tütün tohumlarına laboratuvar koşullarında priming, polimer, priming+polimer uygulamaları yapılmış ve daha sonra fide yastıklarına ekim işlemi gerçekleşmiştir. Çalışmada çimlenme gücü (\%), çimlenme hızı (gün), çıkış gücü (\%), çıkış hızı (gün), fide boyu (cm), yaprak sayısı (adet/bitki), gövde çapı $(\mathrm{mm})$, fide sayısı $\left(\mathrm{adet} / \mathrm{m}^{2}\right)$, kök uzunluğu $(\mathrm{cm})$, yaş gövde ve kök ağırlığı ( $\left.\mathrm{g} / \mathrm{bitki}\right)$, kuru gövde ve kök (g/bitki) gibi özellikler incelenmiştir. Araştırma sonuçlarına göre, çimlenme ve çıkış performansı üzerine priming uygulaması en iyi sonucu vermiş̧tir. Fide boyu 14.7-16.8 cm, yaprak sayısı 7.1-8.2 adet/bitki ve gövde çapı 4-4.6 mm arasında değiştiği belirlenmiştir. Fide boyu, gövde çapı, kök uzunluğu, m2'deki fide sayısı özelliklerine ait en yüksek sonuçlar priming+polimer uygulamasından; yaprak sayısı, yaş gövde ağırlığı, yaş kök ağırlığı, kuru kök ağırlığı özelliklerine ait en yüksek sonuçlar ise polimer uygulamasından elde edilmiştir.

Anahtar Kelimeler: Tütün, Priming, Polimer, Çimlenme, Fide

\section{Effect of Some Improvement Pre-Treatment Applied to Tobacco Seed on Germination and Seedling Emergency Performance}

\begin{abstract}
This study was carried out to determine the effects of some improvement pre-treatment applied on tobacco seed on seedling quality. In the trial Izmir-Ozbas tobacco variety was used and experimental design was Randomized Complete Parcel Design with three replications. In the study, germination rate (\%), germination time (day), seedling emergency rate (\%), seedling emergency time (day), lenght of the seedling $(\mathrm{cm})$, number of the leaf (per/plant), stem diameter $(\mathrm{mm})$, healthy seedlings per square (pcs/m2), lenght of the root $(\mathrm{cm})$, fresh stem and root weight $(\mathrm{g} / \mathrm{plant})$, dry stem and root weight ( $\mathrm{g} / \mathrm{plant})$ were evaluated. According to the results, the best germination and seedling performance was obtained in priming application. lenght of the seedling, number of the leaf and stem diameter were 14.7-16.8 cm, 7.1-8.2 per/plant, 4-4.6 mm, respectively. The highest lenght of the seedling, stem diameter, lenght of the root and healthy seedlings per square was obtained in priming+polimer application. Besides the highest number of the leaf, fresh stem and root weight, dry root weight was found in polimer treatment.
\end{abstract}

Keywords: Tobacco, Priming, Polimer, Germination, Seedling

\footnotetext{
* Sorumlu Yazar: Ege Üniversitesi Ziraat Fakültesi Tarla Bitkileri Bölümü, İzmir, Türkiye, ORCID: 0000-0002-6812-9586, sidika.ekren@ege.edu.tr
} 


\section{Giriş}

Tütün, ülkemiz ekonomisinde ve sosyal yapısında çok önemli bir yere sahip olan endüstri bitkisidir. Türkiye'de gerek dış satım gerekse iç tüketim olarak ele alındığında ekonomimizin vazgeçilmez bir gelir kaynağıdır. Dünya'da üretilen 5 milyon ton tütünün $\% 2$ 'sini üreten Türkiye, AB'den sonra 6. sırada yer almakta, bu tütünü üreten ülkeler içerisinde 1. sırada gelmektedir (Anonim, a). 2018 yılı itibariyle ülkemizde üretilen tütünün \% 75'i Ege, \% 10’u Doğu ve Güneydoğu Anadolu, \% 11'i Karadeniz, \% 3’ü Marmara, \% 1'i Akdeniz Bölgemizde üretilmektedir. \% 75'lik pay ile ilk sırada yer alan bölgemizin 2018 yılı üretim miktarı 62.171 kilodur. Üretimde ve ihracatta birinci sırada yer alan Ege Bölgesi'nin 2018 yılı ihracatındaki payı \% 83'dür (Anonim, b). Yukarıda da ifade edildiği gibi, hem üretim hem de ihracat açısından önemli olan Ege Bölgesi tütünleri marka sigaraların yapısında kaliteyi islah eden ve harmanın ayrılmaz bir parçası olarak istenmeye devam edecektir.

Geçmiş yıllara oranla tütüncülüğ̈̈müzde üretim miktarları yanında verim değerlerinin de azaldığı bilinmektedir. Bu azalmanın nedenleri arasında; tütün tarımı ile uğraşan üretici sayısının azalması, üretici yaş ortalamasının 45 yaş ve üzeri olması, fiyat politikaları, tarımsal uygulamalar ve tohum özellikleri başlıcalarıdır (Ekren ve İlker, 2017). Üretimin sürdürülebilirliği açısından da bu azalma önemli bir problem teşkil etmektedir (Çelen ve ark., 2016). Tütün yetiştiriciliğinde uniform, verimli ve kaliteli ürün yetiştirmek yerli ve dış pazar için oldukça önem taşımaktadır. Verimli ve kaliteli üretimde de ilk adım hastalıksız ve pişkin fide elde etmektir. Tohum çimlenmesine ve fidelik aşamasında fide kalitesine günlük sıcaklık ve 1şık, tohumun çimlenme gücü gibi pekçok faktör etki etmektedir (Liu ve ark., 2003; Jin ve ark., 2014). Fide kalitesi ürün uniformitesi, ürün verimi ve kalitesi açısından çok önemlidir (Kabranova ve ark., 2014).

Tütün yetiştiriciliğinde yaprak tütün kalitesinin yüksek olmasının yanı sıra veriminde yüksek olması ürün fiyatını etkileyen en önemli unsurdur. Ancak üretici için her yıl aynı kalitede ve verim miktarında ürün elde etmek kolay bir iş değildir. Fidelik ve tarla döneminde karşılaşılan hastalık ve zararlılar, tarla toprağının yapısı, üretilen tohum çeşidinin özellikleri, tarla koşullarında ortaya çıkan düzensizlikler, tütün bitkisinin gelişmesi ve kurutma yöntemleri son ürünün verim ve kalitesi üzerine etkili olmaktadır.

Araştırma konusunun materyali Türkiye'de uzun yıllardan bu yana çeşitli bölgelerimizde üretimi yapılan ve ülke ekonomisine çok önemli katkıları olan tütün bitkisinin tohumuna uygulanacak bazı iyileştirici ve ön uygulamalarla tohum çimlenmesi ve fide kalitesinin arttırılması ve bu uygulamaların sonuçlarının ilerleyen dönemde üretici boyutuna da aktarılmasını kapsamaktadır. Bu çalışmada Ege Bölgesi tütün üretiminde önemli bir ticari çeşit olan İzmir-Özbaş tütün tohumuna laboratuvar koşullarında uygulanacak olan bazı ön uygulamaların fide kalitesi üzerine etkisinin araştırılması amaçlanmıştır. Priming, polimer, priming+polimer uygulamalarının tohumun çimlenme hızı ve gücüne olan etkisi belirlenmiştir. Ön uygulamadan geçmiş olan tohumların fideliğe ekildikten sonra fide çıkış ve fide kalitesini belirleyici faktörler de saptanmıştır.

\section{Materyal ve Metot}

Araştırma laboratuvar ve fidelik olmak üzere iki aşamada yürütülmüştür.

2.1. Laboratuvar Aşaması: Ege Üniversitesi Tohum Teknolojisi Uygulama ve Araştırma Merkezi’nde gerçekleştirilmiştir.

2.2. Fidelik Aşaması: Denemede fideleri yetiştirilmesi Ege Üniversitesi Ziraat Fakültesi Tarla Bitkileri Bölümü’nde bulunan sabit fidelikte yürütülmüştür.

Araştırmada İzmir-Özbaş tütün çeşidi deneme materyali olarak kullanılmıştır.

\subsection{Laboratuvar Așaması}

\subsubsection{Priming (Ön çimlendirme) Uygulamalart}

Deneme tohumlarına ön işlem olarak osmo ve matriks priming uygulanarak, priming sonrası çimlenme ve çıkış testleri ile her bir tür için uygun priming yöntemi belirlenmiştir. Osmopriming için, havalandırmalı kolon sistemi, matrikspriming için ise vermikulit taşıyıcı ortamına emdirilen KNO3 çözeltisi kullanılmıştır.

Osmotik ön çimlendirme uygulamaları ile uzun yıllar yapılan çalışmalar özellikle havalandırmalı uygulama kabı tekniğinin etkinliğini ön plana çıkartmıştır (Duman ve İlbi, 2001). Bu teknikte, tohumların çözelti içinde askıda tutulabildiği havalandırmalı uygulama kapları (Bubble-coloumn) büyük kullanım alanı bulmuştur. Bu kaplar içindeki çözelti ve tohum 12 karışımına verilen 2 ml/dakika hızındaki hava, tohumların çözelti içinde askıda kalmalarını sağlamaktadır.

Ön çimlendirme uygulamasında kullanılan PEG (Polyethylenglycol) maddesinin moleküler ağırlığının (6000 ppm) oluşturduğu ozmatik basınç, tohum uygulaması sırasında kökçük çıkışını kontrol atında tutmaktadır. PEG ağır ve yüksek moleküler ağırlığı ile oluşturduğu basınç sayesinde tohum içine belirli orandaki suyun girişine izin verirken, tohum içi ve dış ortam arasında sağlanan denge sonucunda tohum içine daha fazla suyun girişine izin vermemekte ve böylece kökçük çıkışı baskı altında tutulmaktadır. Ayrıca PEG etkili madde olarak hücre duvarından içeri girmez ve tohum üzerinden çok çabuk yıkanarak ayrıştırılabilmektedir. Araştırmada, uygun PEG-6000 dozunun ve priming sürelerinin belirlenmesi amacıyla ön deneme gerçekleştirilmiş̧ir. Ön deneme olarak havalandırmalı uygulama kabına, geçirgen kap içinde yerleştirilen tohumlar, literatürde belirtilen 2.3.6.14.16 ve 24 saatlik sürelerde PEG'in basınç oluşturacak dozlarına (-0.4,-0.8,-1.2,-1.5 ve -1.6 Mpa'lık) ayrı ayrı maruz bırakılmıştır. Her bir süre sonunda tohumların çimlenme durumları kontrol edilmiş, priming esnasında çimlenmenin görüldüğü doz ve süre iptal edilmiştir. Daha sonra tohumlar, 4 dakika çeşme suyunda yıkanmış ve sonra saf su ile durulanmıştır. 2 saat kurutma işlemi yapılmıştır. 


\subsubsection{Tohum Kaplama Uygulamalart}

Tohum kaplama uygulamaları Cimbria CCLAB tohum film kaplama makinasında gerçekleştirilmiş̧ir. Tohumlar polimer önerilen dozlarda ayrı ayrı kaplanmıştır. Kaplama uygulamaları sonunda çimlenme ve çıkış testleri ile değerlendirme yapılmıştır.

Kaplama işlemi sırasında tohumlar makinenin tohum girişi haznesinden makinenin içerisine konulmuş ve şırınga yardımıyla sisteme belirlenen dozlarda polimer ve saf su gönderilmiştir. Aynı zamanda kaplama solüsyonu ile tohumların çeperlere yapışmasını engellemek amacı ile makineye bağlı kompresörden içeriye işlem sırası boyunca hava girişi sağlanmıştır. Kaplama işlemi tamamlandıktan sonra tohumlar kurutma kağıtları üzerine alınmış ve oda sıcaklığında orijinal ağırlıklarına gelene kadar kurumaya bırakılmıştır.

\subsubsection{Kombine Uygulamalar}

Ozmatik tohum uygulamaları (priming), film kaplama uygulamaları birbirleriyle kombine olarak uygulanmıştır. İzmir-Özbaş tütün çeşidine çimlenme ve çıkış performansını arttırmak için uygulanan iyileştirici ön uygulamalar aşağıda belirtilmiştir:
1. Kontrol
2. Priming
3. Polimer

4. Priming+ polimer'dir.

\subsection{4. Çimlendirme Testleri}

Tohumlar uygulama görmeden önce şahit olarak kullanılmak üzere (kontrol tohumları) çimlenme gücü ve hızını belirlemek için ISTA kurallarında belirtildiği gibi çimlenme testine tabi tutulmuşlardır (ISTA, 2014). Aynı test, yapılan tohum uygulamalarından sonra bu kez muamele görmüş tohumlara uygulanmıştır. Çimlendirme testleri için tüm tohumlar ayrı ayrı petri kaplarında ve çift katlı kurutma kağıdı üzerinde 4 tekerrürlü ve her bir tekerrürde 100 adet tohum olacak şekilde çimlendirme testine alınmışlardır. Tüm tohumların çimlenme testleri, optimum $20^{\circ} \mathrm{C}$, sıcaklık koşulunda, soğutmalı inkübatörlerde yürütülmüştür. Çimlenme testleri 21 gün sürdürülmüş, 7. ve 10. günlerde ara değerlendirmeler yapılmıştır. (ISTA, 2014).

Ortalama çimlenme zamanının tespiti için çimlenme testleri süresince sayımlar günlük olarak yapılmış ve kökçüğü $2 \mathrm{~mm}$ olan tohum “çimlenmiş” olarak kabul edilerek sayılmış ve petri kabından uzaklaştırılmıştır. (Duman ve İlbi, 2001).

Çimlenme testleri sonucunda günlük sayımlar toplanarak ve tekerrürlerin aritmetik ortalaması alınarak çimlenme gücü (\%) değeri hesaplanmıştır (Larsen and Andreasen, 2004 ).

$$
\mathrm{ÇG}=\Sigma \mathrm{n} / \mathrm{N} \times 100
$$

$\mathrm{n}:$ çimlenen/çıkış yapan tohum sayısı

$\mathrm{N}$ : toplam tohum sayis1

Çimlenme hızının hesaplanması amacıyla, yapılan günlük sayımlar kullanılarak Pedersen et al., (1993)'in belirttiği eşitlik yardımıyla ortalama çimlenme zamanı gün cinsinden belirlenmiştir. Bu eşitlik için aşağıda belirtilen formülden yararlanılmıştır.

Ortalama çimlenme zamanı $(C ̧ 50)=\Sigma(\mathrm{gx} * \mathrm{nx}) / \Sigma \mathrm{nx}$

gx : testin başlangıcından itibaren sayımın yapıldığı gün

$\mathrm{nx}$ : sayımın yapıldığı gün çimlenen tohum sayısı

इnx : toplam çimlenen tohum sayısı

\subsection{Fidelik Aşaması}

Çalışma 2018 Kasım - 2019 Mart tarihleri arasında Ege Üniversitesi Ziraat Fakültesi Tarla Bitkileri Bölümü uygulama arazisi fideliklerinde yürütülmüştür. Ekim öncesi fidelikte yabancı ot yoğunluğunu azaltmak için solarizasyon işlemi yapılmıştır. Tütün tohumları 1/3 kum+1/3toprak+1/3 çiftlik gübresi ile hazırlanmış fidelik harcına tohumlar $\mathrm{m}^{2}$ ye $1 \mathrm{gr}$ tohum gelecek şekilde 7 Aralık 2018 tarihinde elle serpilerek ekilmiş ve üzeri kapak gübresi ile örtülmüştür. Deneme tesadüf blokları deneme desenine göre 3 tekerrürlü olarak kurulmuştur. Parsel boyutları $35^{*} 110 \mathrm{~cm}$ 'dir. Fidelikte sulama, havalandırma, ot alma vb kültürel işlemler fide durumuna ve hava koşullarına göre düzenli aralıklarla yapılmıştır. Fidelikte herhangi bir hastalık yada zararlı ile karşılaşılmadığı için herhangi bir ilaçlama yapılmamıştır.

\section{Çalışmanın laboratuvar ve fidelik aşamasında:}

Çimlendirme gücü (\%), çimlendirme hızı (gün), çıkış gücü (\%), çıkış hızı (gün), fide boyu (cm), yaprak sayısı (adet/bitki), gövde çapı (mm), $\mathrm{m}^{2}$ deki fide sayısı (adet), kök uzunluğu (cm), yaş gövde ağırlı̆̆ı (g/bitki), kuru gövde ağırlığı (g/bitki), yaş kök ağırlığı (g/bitki), kuru kök ağırlığı (g/bitki) gibi parametreler incelemeye alınmıştır. Sonuçların istatistiki değerlendirmesi TotemStat İstatistiki programında varyans analizine göre yapılmıı̧tır (Açıkgöz ve ark., 2004). 


\section{Araştırma Sonuçları ve Tartışma}

Çalışmada çimlenme gücü, çimlenme hızı, çıkış gücü ve çıkış hızı sonuçlarına Şekil 1, 2, 3 ve 4'de gösterilmiştir. Çimlenme gücü bakımından incelenen özellikler istatistiki bakımdan önemsiz bulunmuştur. Priming uygulamasının çimlenme hızı kontrole göre daha yüksek bulunmuş̧ur. Priming uygulamasında çimlenme gücü \%85 kontrolde ise $\% 82$ olarak saptanmıştır (Şekil 1).

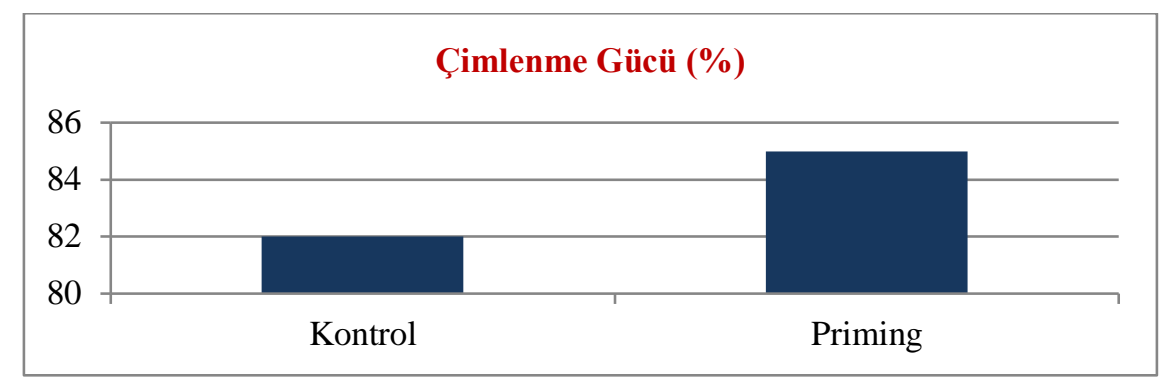

Şekil 1. Tütün Tohumlarının Çimlendirme Gücü (\%)

Çimlenme hızı bakımdan istatistiki olarak yapılan uygulamalar bakımından $\mathrm{p}<0.01$ 'e göre önemli bulunmuştur. Kontrol tohumları 4.74 günde çimlenmesine rağmen priming uygulaması yapılan tohumlar 2.75 günde çimlenmiştir (Şekil 2).

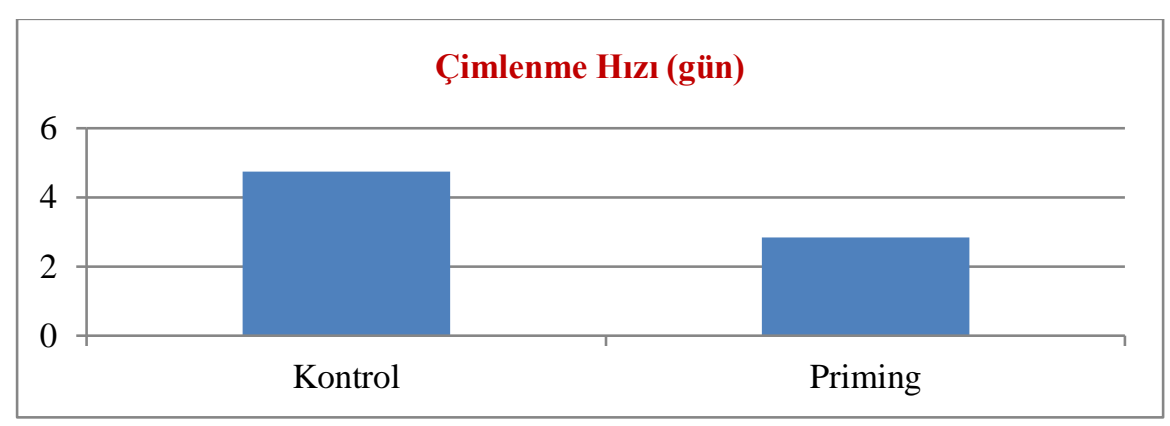

LSD $0,067^{* *}$

Şekil 2. Tütün Tohumlarının Çimlendirme Hızı (gün)

Şekil 3 ve 4'de de görüldüğü gibi, hem çıkış gücü hem de çıkış hızı en yüksek priming uygulaması yapılan tohumlarda bulunmuştur. Polimer uygulaması ise her iki özellik bakımından en düşük sonucu vermiştir. Çıkış gücü \%69-77; çıkış hızı ise 7-11 gün arasında değişen sonuçlar saptanmıştır. Gökçöl ve ark., (2017) bazı Ege tütünlerinin çimlenme gücü, çimlenme hızı, çıkış gücü ve çıkış hızı üzerine yaptıkları çalışmasında çimlenme gücü \%91, çimlenme hızı 1.72 gün, çıkış gücü $\% 80$ ve çıkış hızını ise 1.95 gün olarak tespit etmişlerdir.

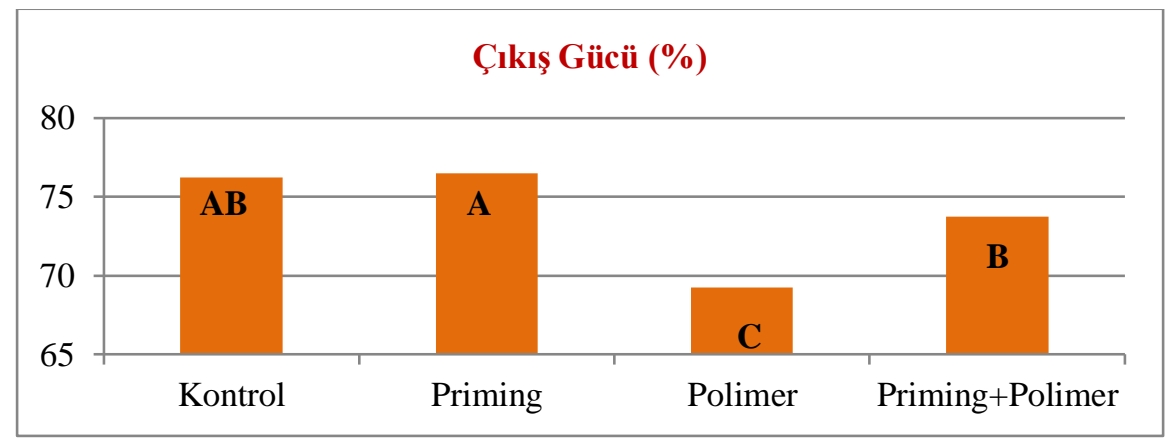

LSD $1,963 * *$

Şekil 3. Tütün Tohumlarının Çıkış Gücü (\%) 


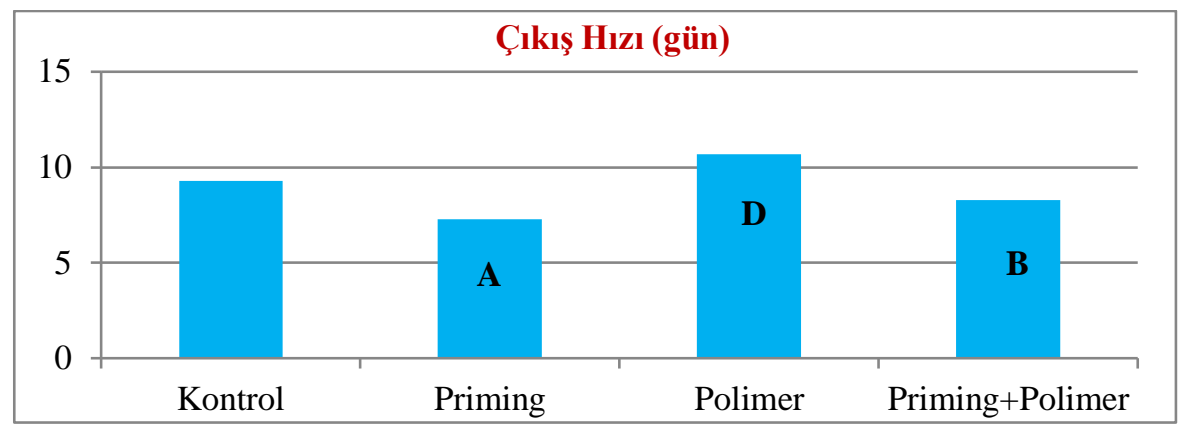

LSD $0,095 * *$

Şekil 4. Tütün Tohumlarının Çıkış Hızı (gün)

Fidelik aşamasına ilişkin incelediğimiz özelliklerde arasında istatistiki açıdan bir fark tespit edilememiş olup rakamsal farklılıklar saptanmıştır.

Fide boyuna ilişkin incelediğimiz özellikler Şekil 4'de gösterilmiştir. Fide boyu 14.7-16.8 cm arasında değiştiği görülmektedir. En uzun fide boyu priming+polimer uygulamasından elde edilmiştir. Fide uzunluğu $\mathrm{m}^{2}$, de bitki sayısına ve uygulanan agronomik işlemlere bağlı olarak değişmektedir (Pearce ve ark., 2005). Fide uzunluğu topraktaki fosfat seviyesi ile ilişkili olduğu ve fosfat miktarının fide kök seviyesindeki büyümeyi etkilediğini belirtmektedirler (Kabranavo ve ark., 2014). Bazı araştırıcılar fide boyunun 6-21 cm arasında değiştiğini tespit etmişlerdir (Turi ve ark., 2004; Ayan ve Çalışkan, 2006; Hou-Long ve ark., 2014, Ekren ve İlker, 2017). Bulduğumuz sonuçların yukarıda belirtilen araştırma bulguları ile uyumlu olduğu görülmektedir.

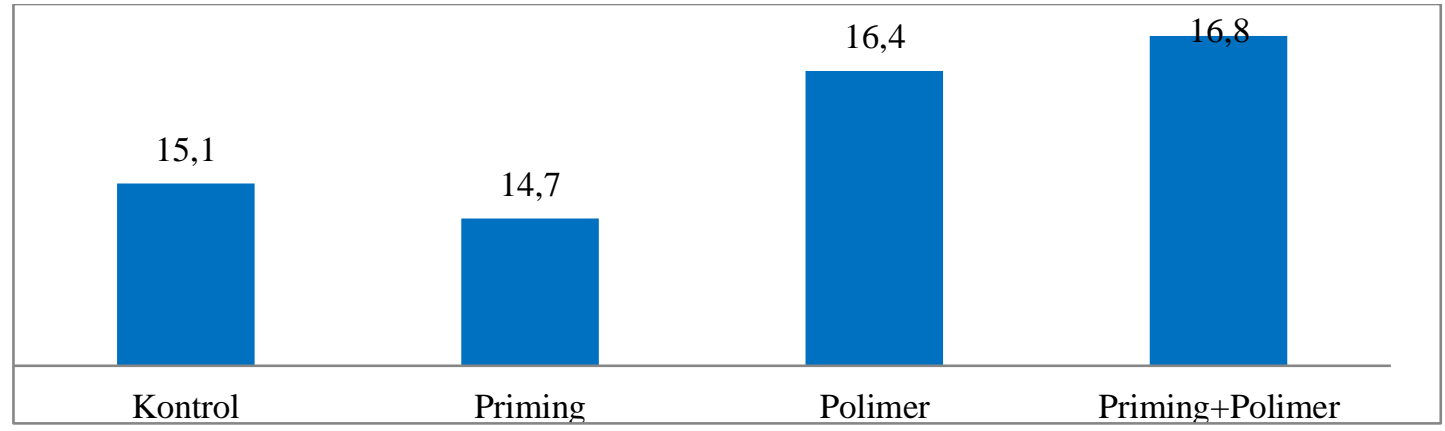

Şekil 4. Tütün Tohumlarına Uygulanan İyileştirici Ön Uygulamaların Fide Boyuna Etkisi (cm)

İncelediğimiz özellikler bakımından en yüksek yaprak sayısı 8.2 adet/bitki ile polimer uygulamasından elde edilirken en düşük yaprak sayısı ise 7.1 adet/bitki ile priming uygulamasından tespit edilmiştir (Şekil 5). Fide yaprak sayısına ilişkin yapılan literatür incelemesinde Ekren ve Yalman (2019) Ege tütünlerinde 7.8-8.4 adet/bitki olarak belirlemişlerdir.

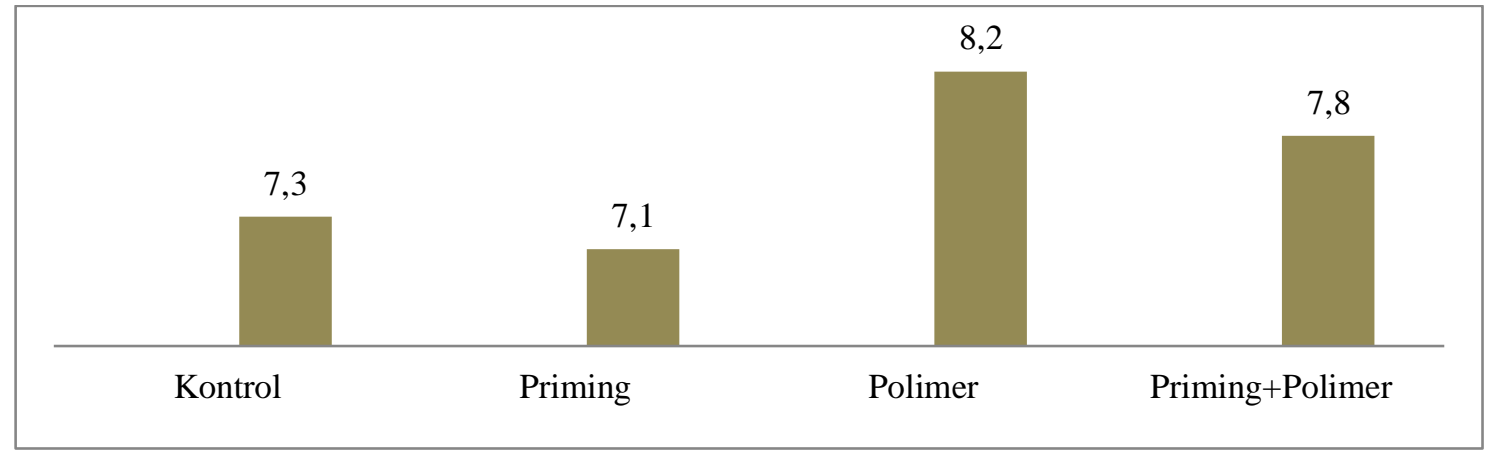

Şekil 5. Tütün Tohumlarına Uygulanan İyileştirici Ön Uygulamaların Yaprak Sayısına Etkisi (adet/bitki) 
Gövde çapı bakımından Şekil 6'ya bakıldığında, 4-4.6 mm olarak değiştiği görülmektedir. Kontrol ve priming uygularında 4 mm, polimer'de $4.5 \mathrm{~mm}$, priming+polimer'de ise 4.6. mm gövde çapı bulunmuştur. Kabranova ve ark., (2014)'e göre, gövde çapının bitkinin gelişmesi bakımından önemli olduğu ve Prilep NS72 ve Yaka 125/3 tütün çeşitlerinde gövde çapının 4.1-5.7 mm arasında değiştiğini tespit etmişlerdir. Turi ve ark., (2004), gövde çapının 2.6-4.1 mm arasında bulmuşlardır. Bulduğumuz sonuçların belirtilen araştırıcıların bulgularıyla uyumlu olduğu belirlenmiştir.

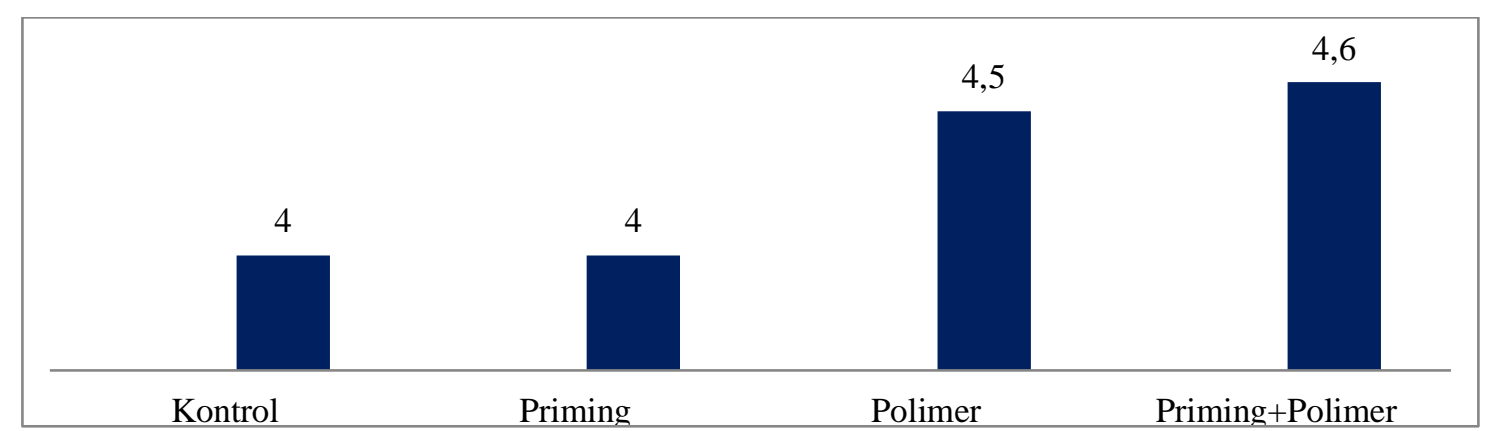

Şekil 6. Tütün Tohumlarına Uygulanan İyileştirici Ön Uygulamaların Gövde Çapına Etkisi (mm)

Kök uzunluğu kontrol ve priming uygulamalarında polimer ve priming+polşmer uygulamalarına göre daha düşük bulunmuştur. Kontrol ve priming uygulamalarında $3.2 \mathrm{~cm}$, poilmer $4.1 \mathrm{~cm}$ ve priming+polimerde ise $4.4 \mathrm{~cm}$ olarak belirlenmiş̧ir (Şekil 7). Ekren ve ark. (2017) Ege tütünleri ile ilgili yaptıkları çalışmasında kök uzunluğunu 2.0-3.5 cm arasında tespit etmişlerdir. Bulduğumuz sonuçlar belirtilen araştırıcıların sonuçlarında uyumludur.

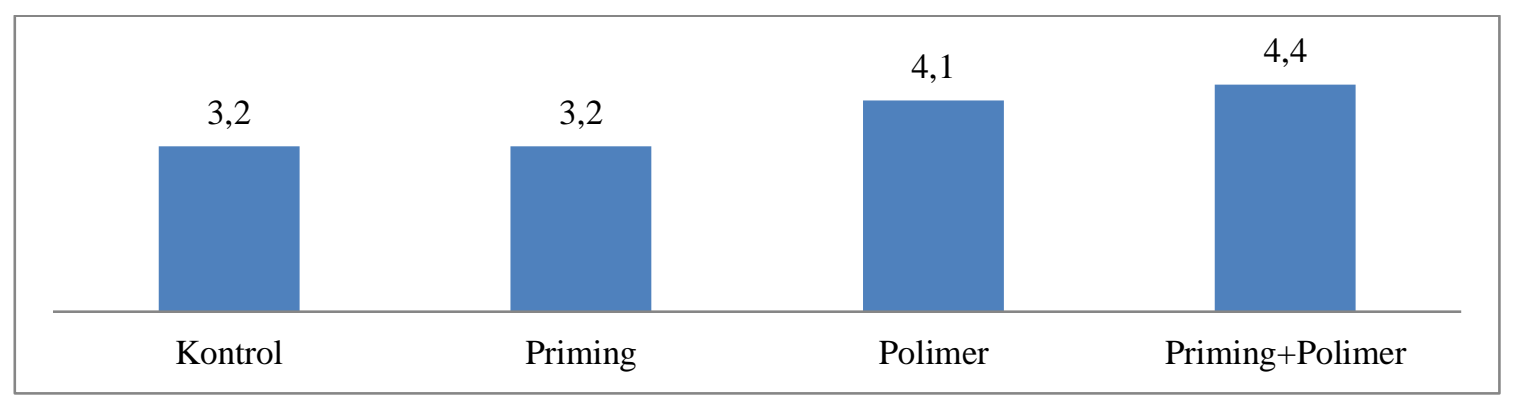

Şekil 7. Tütün Tohumlarına Uygulanan İyileştirici Ön Uygulamaların Kök Uzunluğuna Etkisi (cm)

Şekil 8 incelendiğinde, kullanılabilir fide sayısı bakımından kontrol, priming ve polimer uygulamalarında birbirine yakın sonuçlar saptandığı belirlenmiştir. Priming+polimer uygulamasında ise $8 \mathrm{adet} / \mathrm{m}^{2}$ ile en yüksek sonuç elde edilmiştir. Ekren ve İlker (2017) Ege tütünleri ile ilgili yaptıkları çalışmasında fide sayısını 18-24.7adet/bitki olarak belirlemişlerdir. Bulduğumuz sonuçlar Ekren ve İlker (2017)'den daha düşük bulunmuştur.

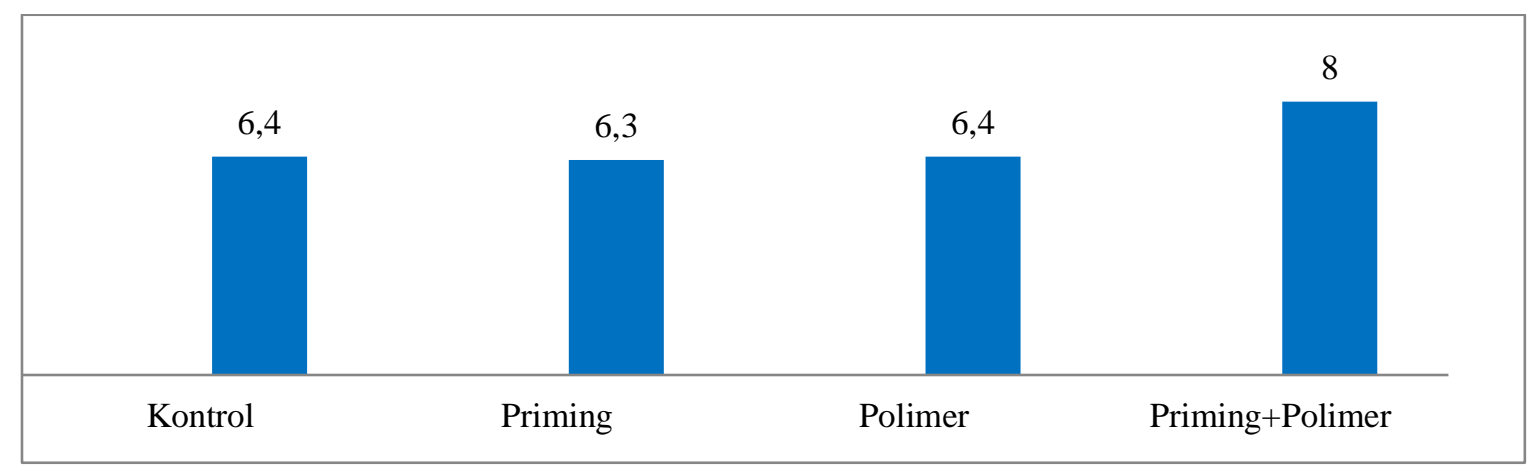

Şekil 8. Tütün Tohumlarına Uygulanan İyileştirici Ön Uygulamaların Kullanılabilir Fide Sayısına Etkisi (adet $\left./ \mathrm{m}^{2}\right)$

Yaş kök ağırlığı en düşük $0.32 \mathrm{~g} /$ bitki ile priming, en yüksek ise $0.68 \mathrm{~g} / \mathrm{bitki}$ ile polimer uygulamasından saptanmıştır. Kontrol 0.5 $\mathrm{g} /$ bitki ve priming+polimer $0.45 \mathrm{~g}$ /bitki ile bu uygulamaları takip etmiştir (Şekil 14). Ekren ve ark., (2017) Ege tütünleri ile ilgili e-ISSN: 2148-2683 
yaptıkları çalışmada yaş kök ağırlıklarını 0.11-0.17 g/bitki olarak tespit etmişlerdir. Bulduğumuz sonuçlar Ekren ve ark., (2017)'den daha yüksek belirlenmişstir.

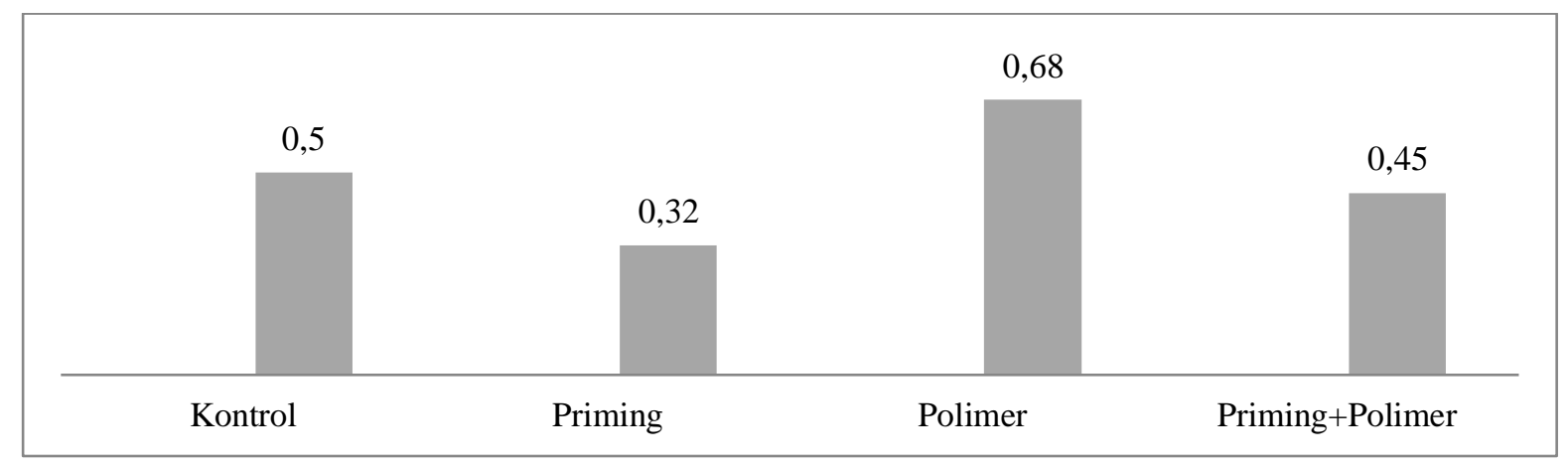

Şekil 9. Tütün Tohumlarına Uygulanan İyileştirici Ön Uygulamaların Yaş Kök Ağırllğına Etkisi (g/bitki)

En düşük kuru kök ağırlıkları sırasıyla polimer $0.14 \mathrm{~g} /$ bitki, kontrol $0.1 \mathrm{~g} / \mathrm{bitki}$, priming+polimer $0.07 \mathrm{~g} /$ bitki ve priming 0.05 $\mathrm{g} /$ bitki olarak bulunmuştur (Şekil 15). Kuru kök ağırlığına ilişkin yapılan literatür incelemesinde Ege tütünlerinde 0.023-0.036 g/bitki olarak tespit etmişlerdir (Ekren ve Yalman, 2019). Bulduğumuz sonuçlar belirtilen literatür değerinden daha yüksek değerler vermiştir. Burada uygulanan işlemlerin ve örneklemenin etkili olduğu düşünülmektedir.

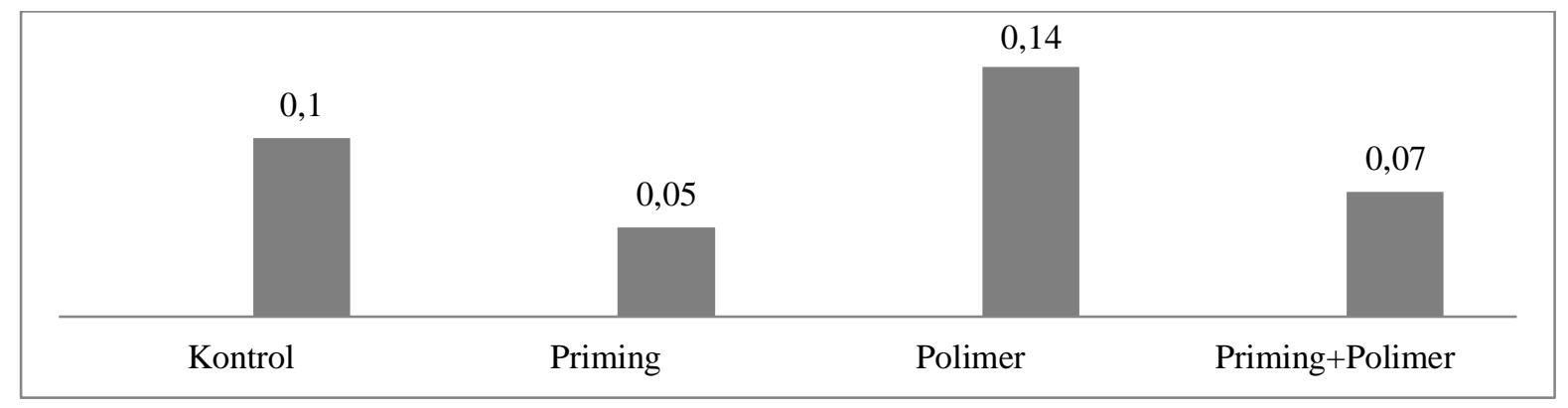

Şekil 10. Tütün Tohumlarına Uygulanan İyileştirici Ön Uygulamaların Kuru Kök Ağırlığına Etkisi (g/bitki)

\section{Sonuç}

$>$ Mevcut çalışmada fide çıkış gücü ve çıkış hızı üzerine priming uygulaması kontrol, polimer ve priming+polimer uygulamalarına göre daha iyi sonuç vermiştir.

$>$ Fidelikte yapılan ölçüm ve tartımlarda istatistiki açıdan fark bulunmamıştır. Rakamsal açıdan farklılıklar söz konusudur.

$>$ Fide boyu, gövde çapı, kök uzunluğu, $\mathrm{m}^{2}$ 'deki fide sayısı özelliklerine ait en yüksek sonuçlar priming+polimer uygulamasından; Yaprak sayısı, yaş gövde ağırlı̆̆ı, yaş kök ağırlığı, kuru kök ağırlığı özelliklerine ait en yüksek sonuçlar ise polimer uygulamasından elde edilmiştir. Bu sebeple bu iki uygulamadan birinin tercih edilmesi gerekmektedir.

\section{Teşekkür}

Bu araştırma projesini (FLP-2018-20381) destekleyen Ege Üniversitesi Bilimsel Araştırma Projeleri (BAP) Koordinasyon Birimi'ne teşekkür ederiz.

\section{Kaynakça}

Açıköz. N., E. İlker, A., Gökçöl, 2004. Biyolojik araştırmaların Bilgisayarda Değerlendirilmeleri E.Ü. Tohum Teknoloji Uygulama ve Araştırma Merkezi Yayın No:2 Bornova/İzmir.

Anonim, 2019. www.meteor.gov.tr

Anonim, a; www.universalcorp.com (Erişim tarihi: 22 Ekim 2018)

Anonim, b; www.tapdk.gov.tr (Erişim tarihi: 22 Ekim 2018)

Celen, A.E., S. Ekren, V. Koparan and E. Ilker. 2016. The effects of different planting methods on tobacco quality yield and yield parameters. "Coresta Congress, Agronomy\&Leaf Integrity and Phytopathology\&Genetics" 9-13th October 2016. Berlin/Germany

Duman, İ., ve lbi, H., 2001. Bazı sebze tohumlarının optimum önçimlendirme sürelerinin ve yöntemlerinin belirlenmesi. E.Ü. Araştırma Fonu 99-ZRF-002 nolu proje sonuç raporu, s: 81. 
Gökçöl A., Ekren S., İlker E., 2017."Investigation on the Improvement of Germination and Seedling Emergency Performances on Some Oriental Type Tobacco Seeds.", International Conference on Agriculture Forest Food Sciences and Technologies ICAFOF Cappadocia/TURKEY.

Ekren, S., 2007. Ege Bölgesi Tütünlerinde Verim ve Kalitenin Değişmesinde Etken Olan Faktörlerin Araştırılması. E.Ü. Fen Bil. Enst. Doktora Tezi. Bornova/İzmir.

Ekren, S., E. İlker, K.E. Köseoğlu, 2017. Bazı Oriental Tütün Çeşitlerinde Clipping Uygulamasının Verim ve Verim Öğelerine Etkisi Üzerine Bir Araştırma. E.Ü. Bilimsel Araştırma Projesi Sonuç Raporu. Proje No: 2014-ZRF-023. Bornova/İzmir

Ekren, S., E. İlker, 2017. The Influence of Clipping Application on Yield and Some Yield Parameters of Aegean Types Tobaccos. Turkish Journal of Field Crops 22(2), 218-226.

Ekren, S., H. B. Yalman, 2019. Effects of Some Plants Nutrients Applied to Seedbed Compost on Seedling Quality. Avrupa Bilim ve Teknoloji Dergisi. Sayı: 16. ss.515-521

Hou-Long, J., 1. Na-Jia, X. An-ding, Y. Chao, W. Hong-Feng, C. Hai-Tao, S. Pei-Xiang, D. Wei. 2014. Development of Closed-Type Transplant Production System and Discussion of its Application Mode for Flue-cured Tobacco. Australian Journal of Crop Science. AJCS 8(11): 1566-1570. ISSN:1835-2707.

ISTA. 2014. International Rules For Seed Testing. Edition 2014. International Seed Testing Association. ISTA. Zurich. Switzerland.

Jin, X., B. W. Tiian and F.L. Chen. 2014. Comparative study on intensive three-dimensional breeding and floating seedling raising of flue-cured tobacco. J. Henan agric. Sci. 43(5):62-65.

Kabranavo, R., Z. Arsov, Z. Dimov and M. Spirkovska. 2014. Impact of Float Tray Technology on Quality of Oriental Tobacco Seedling. 49th Croatian\&9th International symposium on Agriculture. P.362-366. Dubrovnik/Croatia.

Larsen S, Andreasen C. 2004. Light and Heavy Turf-Grass Seeds Differ İn Germination Percentage And Mean Germination Thermal Time. Crop Science 44: 1710-1720.

Liu G. S., X. Y. Xi and x. D. Shi. 2003. Studies on basical growth rules of flue-cured tobacco seedlings in the floating system. Acta Agrice Boreali-sinica. 18(3):36-40.

Pearce, B., g. Palmer, W. Nesmith, L. Townsend. 2005. Guide management of tobacco float systems, Cooperative Extension ServiceUniversity of Kentucky-Clooege of Agriculture. ID-132; pp.8.

Pedersen LH, Jorgensen PE, Pulsen I. 1993. Effect of Seed Vigor and Dormancy on Field Emergence. Development and Grain Yield of Winter Wheat (Triticum aestivum L.) and Winter Barley (Horedeum vulgare L.). Seed Science \& Technology.1:159-178s.

Turi, I., D. Hamel, H. Mesi, R. Sanz, V. Radulovi. 2004. Phase out of Methyl Bromide in Production of Tobacco Seedlings in Croatia. Tütün/Tobacco. Vol:54, No:11-12, 252-256. ISSN: 0494-3244. 